\title{
HOW I LEARNED TO LOVE NORMAL-MODE ROSSBY-HAURWITZ WAVES
}

\author{
Roland A. Madden
}

This paper describes the beginning of the author's interest in normal-mode Rossby-Haurwitz waves and presents some new evidence of them.

D uring the 1960s several discoveries were made that were of major importance to tropical meteorology. Matsuno (1966) published his theory of waves on an equatorial $\beta$ plane. Yanai at Tokyo University and Wallace at the University of Washington and their colleagues discovered mixed Rossby-gravity waves (Yanai and Maruyama 1966; Maruyama 1967) and Kelvin waves (Wallace and Kousky 1968) in the stratosphere that were predicted by Matsuno's theory. In addition, they showed how spectral analysis could be used effectively to detect and to describe these and other synoptic-scale tropospheric waves (e.g., Yanai et al. 1968; Wallace and Chang 1969; Wallace 1971).

AfFILIATIONS: MADDEN*_NCAR, Boulder, Colorado *Emeritus.

CORRESPONDING AUTHOR: Roland A. Madden, rmaddenco@yahoo.com

The abstract for this article can be found in this issue, following the table of contents.

DOI:10.II75/BAMS-D-17-0293.I

A supplement to this article is available online (I0.II75/BAMS-D-17-0293.2)

In final form 3 October 2018

(C)2019 American Meteorological Society

For information regarding reuse of this content and general copyright information, consult the AMS Copyright Policy.
With this as a background, members of the Synoptic Meteorology Group at the National Center for Atmospheric Research (NCAR) began work with Line Islands Experiment (LIE) data. The LIE (February-April 1967) took place in the equatorial Pacific and was the first NCAR-directed large field experiment. It was designed to take advantage of cloud data provided by the first equatorial synchronous geophysical satellite, the Applications Technology Satellite-1 (ATS-1), launched in December 1966, and to learn about scale interactions in the equatorial region (Zipser 1969, 1970).

Accompanying LIE rawinsonde data also presented an opportunity to repeat the aforementioned important observational studies for a new time period. Results of spectral analyses of the LIE rawinsonde data, determined by the lag-correlation method, were reported at the Symposium on Tropical Meteorology at the University of Hawaii in 1970 (Madden 1970). Figure 1 is a photograph of the meeting participants. A key identifying all meeting attendees appearing in Fig. 1 is included in the online supplemental material (see https://doi.org/I0.II75/BAMS-D-17-0293.2).

Results for the lower-stratosphere $v$-wind spectra were consistent with Yanai and Maruyama (1966) and Maruyama (1967), but tropospheric 4-5-day spectral peaks prevalent during April-July 1962 (Yanai et al. 1968) were largely absent during the 


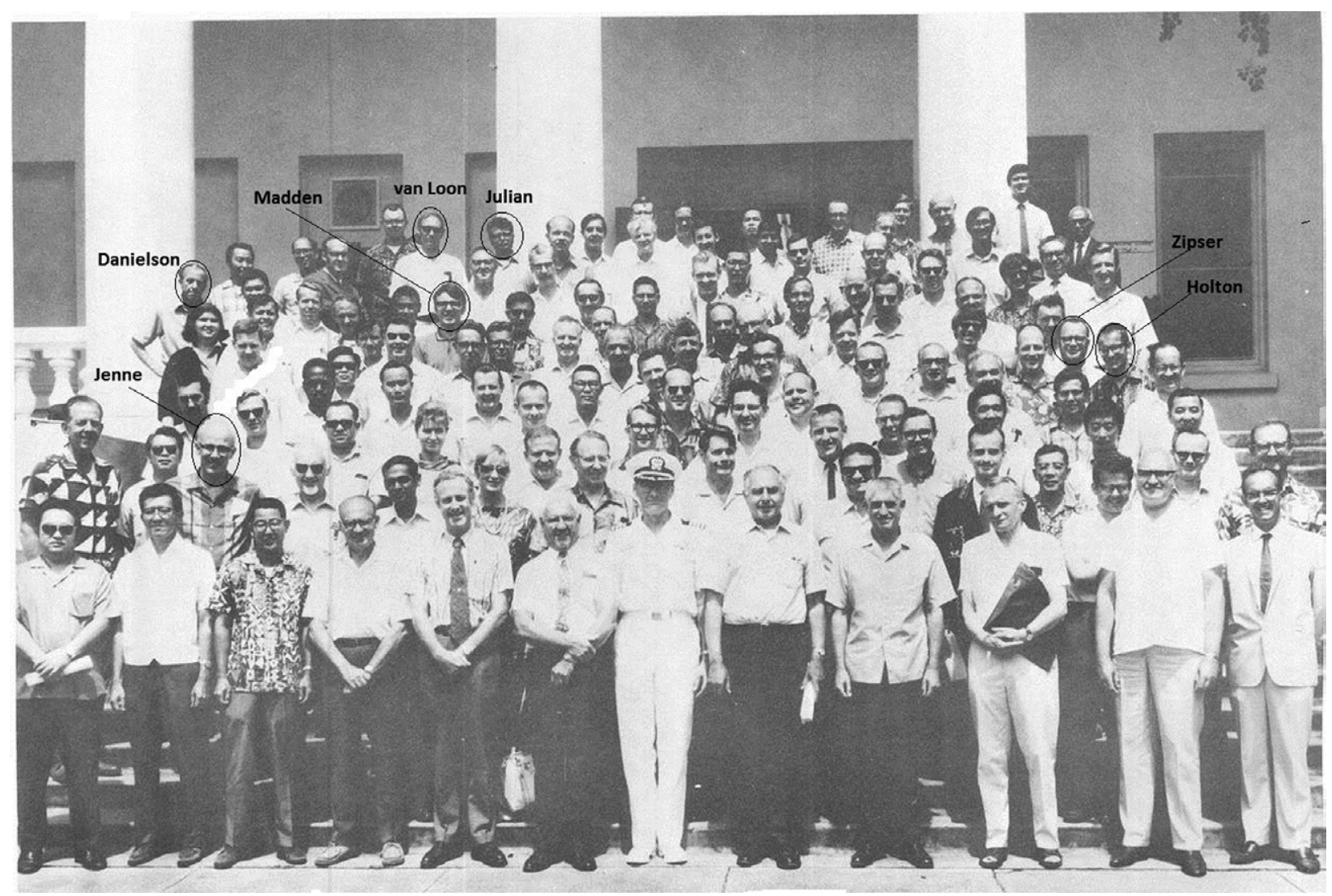

FIG. I. Participants in the Honolulu conference (from Proceedings of the Symposium on Tropical Meteorology, 2-II Jun 1970). Circled persons not mentioned in the text are Harry Van Loon, a member of the NCAR Synoptic Meteorology Group, who was interested in time-averaged waves (Van Loon et al. 1973), and NCAR scientist Ed Danielson, who, with NCAR summer student Robert Gall, wrote the program to reduce LIE rawinsondes.

LIE. Wallace and Chang (1969) had shown variations in results like this during a 2 -yr period that they had examined. It was clear that a study of time variations in a longer record might yield important information. It is difficult to appreciate now, but to gather and process even a 2-yr time series was a major undertaking in the 1960s.

At the same time, Roy Jenne's Data Support Section at NCAR was in the process of gathering longer time series. Also, Paul Julian, an expert on interpreting spectra (Julian 1971), and a member of the Synoptic Meteorology Group, had an early fast Fourier transform (FFT) code written at NCAR. The relatively recent publication of an FFT algorithm (Cooley and Tukey 1965; Cooley 1987) was another fortunate circumstance. A Fourier transform of an $\mathrm{N}$-member series required $N \times N$ complex multiples before the FFT. The FFT needed only $N \times \log (N)$ complex multiples. For a 10 -yr record of daily values the computational reduction was near a factor of 100 . That was important because the fastest computer available to meteorologists at the time was the National Center for Atmospheric Research's (NCAR) Control Data Corporation (CDC)
6600, whose clock speed was only $10 \mathrm{MHz}$, and in 1971 a CDC 7600 with a clock speed of $36 \mathrm{MHz}$. Today, a typical laptop clock speed is in the gigahertz range.

Upon our return from the Hawaii meeting, Julian and the author embarked on spectral analyses of NCAR's newly acquired longer records in order to study nonstationary aspects of the LIE results. Instead, very large variations near a 45 -day period that are now often referred to as the Madden-Julian oscillation (MJO) were found (Madden and Julian 1971, 1972a). A cross-spectrum analysis between station pressure at Kanton Island $\left(3^{\circ} \mathrm{S}, 172^{\circ} \mathrm{W}\right)$ and upper-air data from only six equatorial stations revealed planetary-scale circulation cells in the equatorial plane and eastward movement to be associated with these variations, further demonstrating the diagnostic power of the spectral approach. A summary of the cross-spectrum results plotted in Fig. 6 of Madden and Julian (1972a) led to the schematic (Fig. 16 in Madden and Julian 1972a) that is still used to summarize the oscillation's features. More on early explorations of the MJO are contained in Lau and Waliser (2005, chapter 1) and Hand (2015). 
Cross-spectrum analysis between station pressures in the equatorial zone also provided evidence of a zonal wavenumber 1 , westwardpropagating wave with a 5-day period (Madden and Julian 1972b). Poleto-pole plan views of the observed and theoretical "5-day wave" are presented in Madden and Julian (1973, their Fig. 4) and Dickinson (1968, his Fig. 5a), respectively. We learned that this wave had been previously identified and linked to theoretically predicted normalmode Rossby-Haurwitz waves (NMRHWs) (Eliasen and Machenhauer 1965, 1969).

What follows is some new evidence for the existence of NMRHWs in observations. First, results of Kasahara (1980) and Kasahara and Puri (1981) are related to provide theoretical expectations for NMRHWs. Then, results of spectral analyses of vorticity fields from a 3-yr record (2010-12) of European Centre for Medium-Range Weather Forecasts interim reanalysis (ERA-Interim) data determined by readily available NCAR Command Language (NCL) routines are presented. Both theoretical predictions and observations of wave periods are shown for comparison. ${ }^{1}$

\section{THEORETICAL PREDICTIONS OF NOR- MAL-MODE ROSSBY-HAURWITZ WAVES.}

Rossby et al. (1939) isolated the basic dynamics that control an important class of the normal modes: the "waves of the second class," or, in his words, "planetary waves." Haurwitz (1940a,b) extended Rossby's treatment thus the reference "normal-mode Rossby-Haurwitz waves." The theory of normal modes in the ocean
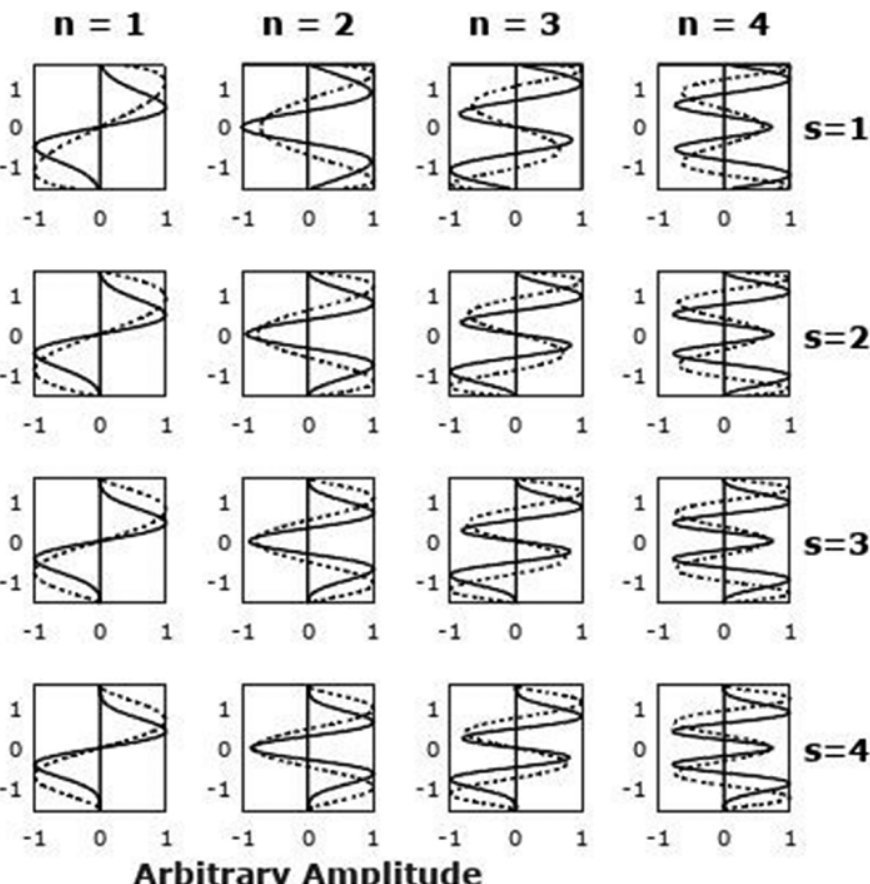

Arbitrary Amplitude

FIG. 2. Dotted lines show latitudinal dependence of single associated Legendre polynomials. Solid lines are the Hough function depictions of the latitudinal pendence of vorticity for different NMRHWs predicted by the Laplace tidal wavenumber $s$ and each column is for a different meridional index $n$. Hough functions are after code described by Swarztrauber and Kasahara (1985).

and atmosphere has a long history dating back to the formulation of the Laplace tidal equation in the early nineteenth century. The theory has been reviewed by Holton (1975) and many others. It suffices to say here that atmospheric NMRHWs can be described as external waves (oscillations in phase in the vertical) with a slight amplitude growth in the vertical [see Kasahara and Puri (1981); their Fig. 2 for an equivalent depth of $9,570 \mathrm{~m}]$, and sums of associated Legendre polynomials, or Hough functions in the horizontal.

For the largest-scale NMRHWs, the leading terms of Hough sums of associated Legendre polynomials are reasonable approximations to the full sums for the meridional structures (Golitsyn and Dikii 1966). For comparison, Fig. 2 presents the latitude dependence of predicted NMRHW vorticity fields depicted by the appropriate Hough function (solid lines) and that depicted by a single associated Legendre polynomial (dotted

\footnotetext{
${ }^{1}$ The new work reported here was first prepared for the 2015 Modes Workshop at NCAR (Žagar et al. 2016). Aside from the fact that results are based on a new dataset (ERA-Interim data) and a new variable (vorticity fields), their summary contained in Fig. 6 points to wave modes that have already been identified in references cited in the review articles mentioned in the text. Nevertheless, it is hoped that the remarkable correspondence between observations and theory presented here in one place will be of general interest. The background information was added for the 2016 Ed Zipser Symposium at the 32nd Conference on Hurricanes and Tropical Meteorology in San Juan, Puerto Rico, to show how LIE data collected under Zipser's direction as Chief Scientist led the author to an interest in NMRHWs.
} 
lines), the approximation used here. The indices $s$ and $n$ are the zonal wavenumber and meridional index, respectively. Included here and in Fig. 3 (see also Fig. 6 to follow) are mixed Rossby-gravity waves in the $n=0$ column, whose dispersion properties for the largest zonal scales are "mixed" between westward inertiagravity waves and NMRHWs. A figure, based on the Swarztrauber and Kasahara (1985) code, showing the latitudinal dependence of NMRHW zonal wind, meridional wind, and geopotential is included in the online supplemental material (see https://doi.org//0.II75 /BAMS-D-17-0293.2).

The largest-scale modes also have discrete predicted frequencies in a global shallow-water model linearized about zonally averaged (symmetric) background winds. Figure 3, adapted from Kasahara (1980), shows expected wave periods in days assuming average December-February (DJF) 500-hPa winds. Kasahara

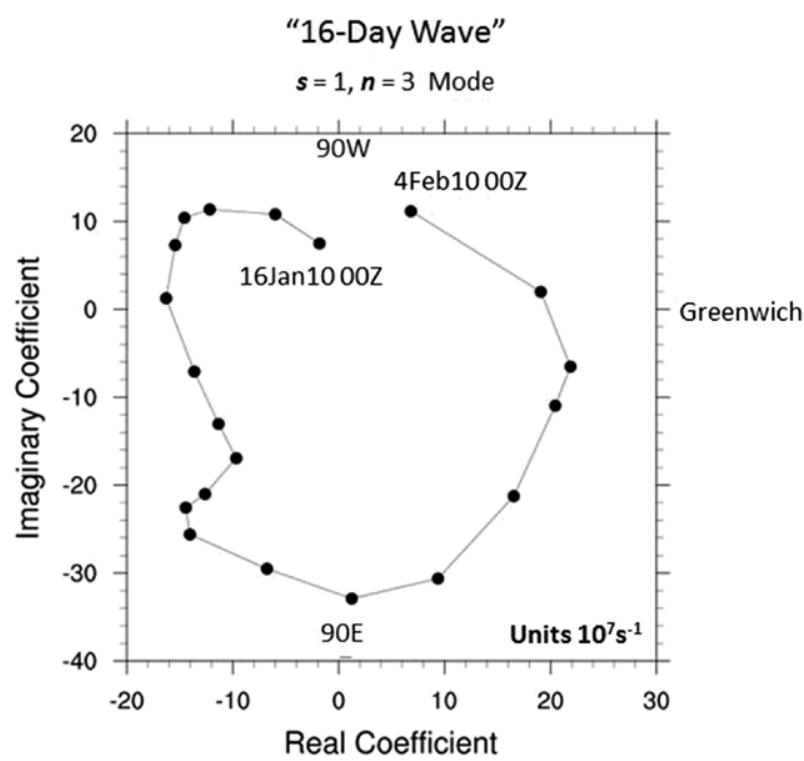

FIG. 4. Hodograph of the $s=I, n=3$ projection (16-day wave) for 19 days during early 2010. Only 0000 UTC observations are plotted. Corresponding Greenwich, $90^{\circ} \mathrm{W}$, and $90^{\circ} \mathrm{E}$ longitudes are indicated. The asymmetric propagation about 0.0 suggests a time-mean projection centered near $90^{\circ} \mathrm{E}$. includes results for background winds from other seasons and the predicted wave periods for most modes differ from DJF ones by less than $10 \%$. The largest difference of $17 \%$ ( 11.18 vs 13.55 days) is between DJF and June-August (JJA) for the $s=4, n=3$ mode.

Baer (1972) has suggested a two-dimensional index $l(l=n+s)$ as a measure of horizontal scale. Constant $l$ values lie along diagonals from the bottom left to the top right in Figs. 2 and 3 (as well as in Fig. 6). We will use $l$ as an approximate indicator of what modes are most likely to be discernible in the observations. For example, Fig. 3 suggests we might find NMRHWs with discrete frequencies for $l \leq 6$ or maybe $7(s=4$, $n=3$ mode).

OBSERVATIONS. Early evidence or NMRHWs is summarized in Madden (1979), Ahlquist (1982), and Salby (1984). For an inventory of published evidence from 1982 to 2007, see Table 5 in Madden (2007). More recently, evidence of NMRHWs has been found in a number of variables, for example, in tropical winds (Hendon and Wheeler 2008) and in observations of the very high atmosphere (Sassi et al. 2012). Data used in the present analyses are four-times-perday $(0000,0600,1200$, and 1800 UTC) vorticity fields.

To approximate the vertical structure of predicted waves, the vorticity data were averaged in the vertical from 850 to $100 \mathrm{hPa}$. This approximation captures the in-phase nature but not Kasahara and Puri's (1981) predicted amplitude growth with height. Next, 
vertically averaged vorticity fields were projected onto the single associated Legendre polynomials shown by the dotted lines in Fig. 2 (using NCL routine shagC) to approximate the Hough horizontal structures. The 5-day wave is, for example, the $s=1, n=1$ projection.

Figure 4 shows a hodograph of the behavior of the $s=1, n=3$ projection, a frequently observed NMRHW also known as the "16-day wave," for a selected 19-day period. Regular westward propagation is evident. The vertical and horizontal filtering has served to isolate this NMRHW with no need for time filtering. If westward propagation is a regular feature, we expect the cross spectra between the real and imaginary spatial coefficients of the $s=1$, $n=3$ projections to show coherence near Kasahara's corresponding predicted period of 18.39 days and the real should lead the imaginary coefficient by onequarter cycle. Hayashi's (1971) "westward variance" reflects these expectations in a single variable.

Westward variance is estimated by $1 / 4[S(f)+C(f)$ $+2 Q(f)$ ] [Eq. (4-4) in Hayashi (1971)], where $S(f)$ and $C(f)$ are the power spectra of the sine and cosine spatial coefficients, respectively, and $Q(f)$ is the quadrature spectrum between them. Spectra and quadrature spectra were determined by the NCL routine specxy_anal. Twenty-nine periodogram estimates were averaged to provide smooth spectra.

Since the time series are each four observations per day for 3 years there are 4,384 observations and 2,192 periodogram estimates between 0.0 and 2 cyles per day (cpd). The resulting frequency resolution is close to $0.026 \mathrm{cpd}$, and the number of degrees of freedom is, to first approximation, $58(29 \times 2)$. The $5 \%$ sampling limit of a null hypothesis of zero coherence is about 0.10 (Julian 1975).
Figure 5 shows the westward variance of the $s=1, n=3$ projections. Coherence squares between real and imaginary spatial coefficients are also plotted in Fig. 5, along with the predicted period (18.39 days) from Kasahara (1980) (listed in Fig. 3 here). Figure 6 shows results similar to Fig. 5 for all of the modes. In Fig. 6, the predicted frequency for $s=5, n=0$ is from Longuet-Higgins (1968, his Fig. 6) for a $10-\mathrm{km}$ equivalent depth. Its corresponding period is shown as " 3.2 days." The Longuet-Higgins result is without background winds, but for the four Rossby-gravity $(n=0)$ waves Kasahara (1980) examined, the largest difference between no-wind and DJF wind cases was only $13 \%(s=4, n=0$ mode with 2.56 days for no wind and 2.90 days for DJF winds), so we can expect the wind effect on the $s=5$, $n=0$ mode to be small. 
Because of the results from the already-mentioned modeling and observational studies, it is not surprising that most of the largest-scale modes (in this case $l \leq 5$ ) show relative maxima westward variance close to the predicted frequencies. Modes with $l=5$ lay along the diagonal from lower left $(s=5, n=0)$ to upper right $(s=1, n=4)$. Modes with small relative maxima in westward variance near predicted frequencies (e.g., $s=4$ and 5 and $n=0, s=3$ and $n=2$ ) have large relative maxima in coherence there, and phase angles (not shown) with the real leading the imaginary spatial coefficient by one-quarter cycle, consistent with westward propagation. In fact, where coherence is high for $l \leq 5$ modes, all corresponding phase angles support westward propagation. On the contrary, for $l>5$ high coherence is accompanied by phase angles with the imaginary leading the real coefficient by one-quarter cycle, consistent with eastward propagation. For three

\section{Westward Variance}

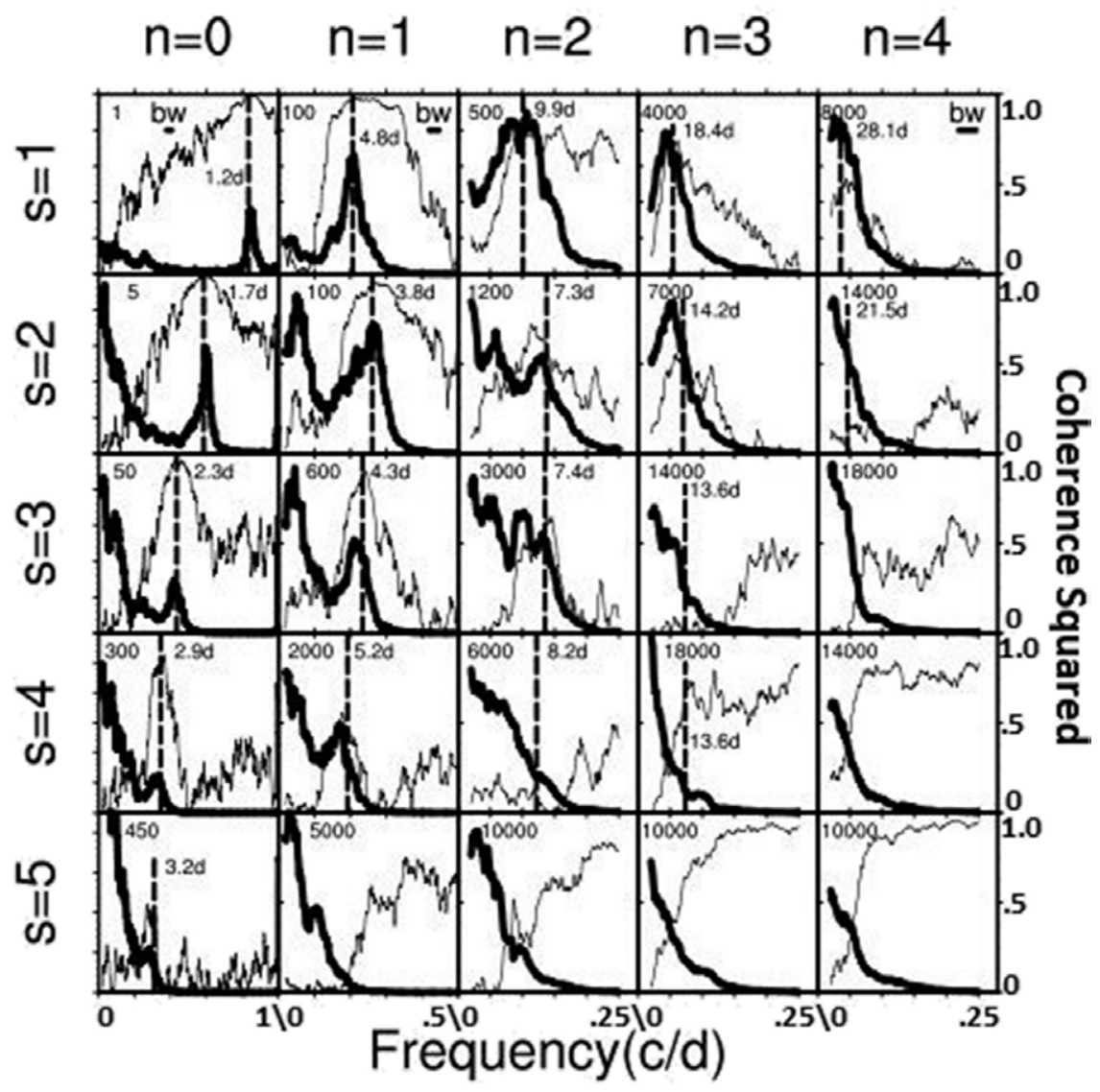

Fig. 6. As in Fig. 5, but for all projections. Predicted periods (days) from Kasahara (1980) and Fig. 3 here are indicated by the dashed vertical line and the accompanying number. Predicted period for $s=5, n=0$ from LonguetHiggins (1968, his Fig. 6) for a $10-\mathrm{km}$ equivalent depth. Highest frequency plotted is Icpd in column I, $0.5 \mathrm{cpd}$ in column 2 , and $0.25 \mathrm{cpd}$ in columns 3-5. Bandwidth (bw) is indicated (top row). Thin (thick) line is the westward variance (coherence squared). of the Rossby-gravity waves, coherence is near 1.0, implying that nearly all of the variability of one spatial coefficient can be explained by the other.

DISCUSSION. Data studied here suggest discrete modes only for $l \leq 5$. Kasahara's (1980) results summarized in Fig. 3 predict the existence of discrete modes for $l=6(s=2, n=4 ; s=3, n=3$; and $s=4, n=2)$ and for $l=7(s=4, n=3)$. There have been reports of observed modes with $l=6$ in the literature. The $l=6$ modes $(s=2$, $n=4$ and $s=4, n=2$ ) were noted by Ahlquist (1982) and Madden (2007). The $l=6$ mode $(s=3, n=3)$ was noted by Lindzen et al. (1984). Previously mentioned reviews contain more references concerning these three modes. While we offer $l=5$ as a typical smallest spatial scale that will allow NMRHWs, that limit will vary depending, presumably, on the changing background flow. Further, there can always be ambiguity about identifying traveling disturbances as NMRHWs. For example, the BranstatorKushnir wave (Branstator 1987; Kushnir 1987) is similar in structure to the $s=1$, $n=3$ mode and in period to the $s=1, n=4$ mode, but Branstator and Held (1995) indicate it is likely an unstable mode rather than neutral NMRHWs. Interestingly, they used a mode tracking method to learn which NMRHWs are most likely to survive in a nondivergent barotropic vorticity model linearized about wavy (asymmetric) November-March, 300-hPa flows. They found that modes likely to maintain a reasonable resemblance to the no-wind NMRHWs all have $l \leq 5$ (their Table 2).

It is important to stress that evidences for NMRHWs are not necessarily dependent on reanalysis products. NMRHWs were seen in data that preceded objective analysis (e.g., Kubota and Iida 1954; Deland 1964; and some other references above). 
More recently, they have been seen in new measuring systems (e.g., Rüfenacht et al. 2016).

The existence of waves similar to those predicted by Kasahara's linear theory is interesting in itself, but beyond an academic interest why should we care? NMRHWs have been identified in observations for more than 60 years, and even the first barotropic forecast was plagued by a poorly handled NMRHW (Charney and Eliassen 1949). Further, it has been argued that they may play a role in large-scale circulation, fluctuating eddy heat transports, blocking, and even motions of Earth's poles, and, yet, during all this time the notion that NMRHWs may be of practical importance has not taken hold.

The ease with which NMRHWs can now be isolated using readily available software may allow researchers to be more convincing in defining important practical consequences of NMRHWs.

For example, the role that they may play in local weather needs further exploration. Already, there is considerable evidence that, despite its small associated convergence, the 5 -day wave affects tropical convection (Burpee 1976; Patel 2001; King et al. 2015, 2017). King et al. (2015) argue that it is not large-scale convergence associated with the 5-day wave but rather the interaction of its associated wind field with local terrain that is the defining influence. Careful studies of other modes may reveal additional important effects on local weather.

SUMMARY. Members of the Synoptic Meteorology Section at NCAR were looking at LIE data after Matsuno, Yanai, and colleagues and after Wallace and colleagues had opened doors to the theory and diagnoses of tropical waves. Following their lead, work on the LIE led to analyses of long time series with Julian. This, in turn, led to the MJO and a beginning interest in NMRHWs by the author. Here, expectations of NMRHW were outlined based on the theory and modeling of Kasahara (1980) and Kasahara and Puri (1981). ERA-Interim data were analyzed and the largest scale modes with $n+s=l \leq 5$ are identified. We think it is an important advance that routines are readily available to isolate NMRHWs. Here, NCL routines were used to provide rough approximations, but code that provides perfect fidelity to the Kasahara-Puri predictions is now available (Žagar et al. 2015).

ACKNOWLEDGMENTS. D. Shea prepared the basic vorticity data. A. Kasahara and R. Valent provided code used to compute Fig. 2. G. Kiladis, J. M. Wallace, and G. Branstator made helpful comments on an earlier version of the paper. All the official reviewers took considerable time to offer many constructive suggestions for improvement. Discussions with J. Tribbia and N. Zagar helped to clarify for me several aspects discussed herein. The National Center for Atmospheric Research is sponsored by the National Science Foundation.

\section{REFERENCES}

Ahlquist, J., 1982: Normal-mode global Rossby waves: Theory and observations. J. Atmos. Sci., 39, 193202, https://doi.org/10.1175/1520-0469(1982)039 $<0193:$ NMGRWT $>2.0 . C O ; 2$.

Baer, F., 1972: An alternate scale representation of atmospheric energy spectra. J. Atmos. Sci., 29, 649664, https://doi.org/10.1175/1520-0469(1972)029 $<0649$ :AASROA $>2.0 . \mathrm{CO} ; 2$.

Branstator, G., 1987: A striking example of the atmosphere's leading traveling pattern. J. Atmos. Sci., 44, 2310-2323, https://doi.org/10.1175/1520-0469 (1987)044<2310:ASEOTA>2.0.CO;2.

— , and I. Held, 1995: Westward propagating normal modes in the presence of stationary background waves. J. Atmos. Sci., 52, 247-262, https://doi.org/10 $.1175 / 1520-0469(1995) 052<0247:$ W PNMIT $>2.0$ .CO;2.

Burpee, R. W., 1976: Some features of global-scale 4-5 day waves. J. Atmos. Sci., 33, 2292-2299, https://doi.org /10.1175/1520-0469(1976)033<2292:SFOGSD >2.0 .CO;2.

Charney, J. G., and A. Eliassen, 1949: A numerical method for predicting the perturbations of the middle latitude westerlies. Tellus, 1, 38-54, https:// doi.org/10.3402/tellusa.vli2.8500.

Cooley, J. W., 1987: The re-discovery of the fast Fourier transform algorithm. Mikrochim. Acta, 93, 33-45, https://doi.org/10.1007/BF01201681.

— - and J. W. Tukey, 1965: An algorithm for the machine calculation of complex Fourier series. Math. Comput., 19, 297-301, https://doi.org/10.1090/S0025 -5718-1965-0178586-1.

Deland, R., 1964: Traveling planetary waves. Tellus, 16, 271-273, https://doi.org/10.3402/tellusa.v16i2.8895.

Dickinson, R. E., 1968: On the exact and approximate linear theory of vertically propagating planetary Rossby waves forced at a spherical lower boundary. Mon. Wea. Rev., 96, 405-415, https://doi.org/10 .1175/1520-0493(1968)096<0405:OTEAAL >2.0 .CO;2.

Eliasen, E., and B. Machenhauer, 1965: A study of the fluctuations of atmospheric planetary flow patterns represented by spherical harmonics. Tellus, 17, 220-238, https://doi.org/10.3402/tellusa.v17i2.9032. 
_ , and —_, 1969: On the observed large-scale atmospheric wave motions. Tellus, 21, 149-165, https://doi .org/10.3402/tellusa.v21i2.10069.

Golitsyn, G. S., and L. A. Dikii, 1966: Oscillations of planetary atmospheres as a function of the rotational speed of the planet. Izv. Atmos. Ocean. Phys., 2, 225-235.

Hand, E., 2015: The storm king. Science, 350, 22-25, https://doi.org/10.1126/science.350.6256.22.

Haurwitz, B., 1940a: The motion of atmospheric disturbances. J. Mar. Res., 3, 35-50.

- 1940b: The motion of atmospheric disturbances on the spherical earth. J. Mar. Res., 3, 254-267.

Hayashi, Y., 1971: A generalized method of resolving disturbances into progressive and retrogressive waves by space Fourier and time cross-spectral analysis. J. Meteor. Soc. Japan, 49, 125-128, https:// doi.org/10.2151/jmsj1965.49.2_125.

Hendon, H. H., and M. C. Wheeler, 2008: Some spacetime spectral analyses of tropical convection and planetary-scale waves. J. Atmos. Sci., 65, 2936-2948, https://doi.org/10.1175/2008JAS2675.1.

Holton, J. R., 1975: The Dynamic Meteorology of the Stratosphere and Mesosphere. Meteor. Monogr., No. 37, Amer. Meteor. Soc., 218 pp.

Julian, P. R., 1971: Some aspects of variance spectra of synoptic scale tropospheric wind components in midlatitudes and in the tropics. Mon. Wea. Rev., 99, 954-965, https://doi.org/10.1175/1520-0493(1971)099 $<0954$ :SAOVSO>2.3.CO;2.

- 1975: Comments on the determination of significance levels of the coherence statistic. J. Atmos. Sci., 32, 836-837, https://doi.org/10.1175/1520-0469 (1975)032<0836:COTDOS $>2.0$. CO;2.

Kasahara, A., 1980: Effect of zonal flows on the free oscillations of a barotropic atmosphere. J. Atmos. Sci., 38, 2284-2285, https://doi.org/10.1175/1520-0469 (1980)037<0917:EOZFOT>2.0.CO;2; Corrigendum, J. Atmos. Sci., 38, 2284-2285, https://doi.org/10.1175 /1520-0469(1981)038<2284:>2.0.CO;2.

— , and K. Puri, 1981: Spectral representation of threedimensional global data by expansion in normal mode functions. Mon. Wea. Rev., 109, 37-51, https:// doi.org/10.1175/1520-0493(1981)109<0037:SROTDG $>2.0 . \mathrm{CO} ; 2$.

King, M. J., M. C. Wheeler, and T. P. Lane, 2015: Association of convection with the 5-day Rossby-Haurwitz wave. J. Atmos. Sci., 72, 3309-3321, https://doi .org/10.1175/JAS-D-14-0316.1.

,$- \ldots$, and — 2017: Mechanisms linking global Rossby-Haurwitz waves to tropical convection. J. Atmos. Sci., 74, 3679-3702, https://doi.org/10.1175 /JAS-D-17-0101.1.
Kubota, S., and M. Iida, 1954: Statistical characteristics of atmospheric disturbances. Pap. Meteor. Geophys., 5, 22-34, https://doi.org/10.2467/mripapers 1950.5.1_22.

Kushnir, Y., 1987: Retrograding wintertime lowfrequency disturbances over the North Pacific Ocean. J. Atmos. Sci., 44, 2727-2742, https://doi.org /10.1175/1520-0469(1987)044<2727:RWLFDO >2 $.0 . \mathrm{CO} ; 2$.

Lau, K. M., and D. E. Walliser, 2005: Intraseasonal Variability in the Atmosphere-Ocean Climate System. Springer, $436 \mathrm{pp}$.

Lindzen, R. S., D. M. Straus, and B. Katz, 1984: An observational study of large-scale atmospheric Rossby waves during FGGE. J. Atmos. Sci., 41, 13201335, https://doi.org/10.1175/1520-0469(1984)041 $<1320$ :AOSOLS>2.0.CO;2.

Longuet-Higgins, M. S., 1968: The eigenfunctions of Laplace's tidal equations over a sphere. Philos. Trans. Roy. Soc. London, 262A, 511-607, https://doi .org/10.1098/rsta.1968.0003.

Madden, R. A., 1970: Wave disturbances over the equatorial Pacific during the Line Islands Experiment. Proc. Symp. on Tropical Meteorology, Honolulu, HI, Amer. Meteor. Soc., L-VI-1-L-VI-5.

— 1979: Observations of large-scale traveling Rossby waves. Rev. Geophys. Space Phys., 17, 1935-1949, https://doi.org/10.1029/RG017i008p01935.

— 2007 : Large-scale free Rossby waves in the atmosphere-A review. Tellus, 59A, 571-590, https://doi .org/10.1111/j.1600-0870.2007.00257.x.

— , and P. R. Julian, 1971: Detection of a 40-50 day oscillation in the zonal wind in the tropical Pacific. J. Atmos. Sci., 28, 702-708, https://doi.org/10.1175 /1520-0469(1971)028<0702:DOADOI>2.0.CO;2.

$\longrightarrow$, and — 1972a: Description of global-scale circulation cells in the tropics with a 40-50 day period. J. Atmos. Sci., 29, 1109-1123, https://doi.org /10.1175/1520-0469(1972)029<1109:DOGSCC >2.0 .CO;2.

- , and - 1972b: Further evidence of global-scale, 5-day pressure waves. J. Atmos. Sci., 29, 1464-1469, https://doi.org/10.1175/1520-0469(1972)029<1464:FE OGSD $>2.0 . \mathrm{CO} ; 2$.

—, and —, 1973: Reply. J. Atmos. Sci., 30, 935940, https://doi.org/10.1175/1520-0469(1973)030 $<0935: \mathrm{R}>2.0 . \mathrm{CO} ; 2$.

Maruyama, T., 1967: Large-scale disturbances in the equatorial lower stratosphere. J. Meteor. Soc. Japan, 45, 391-408, https://doi.org/10.2151/jmsj1965.45.5_391.

Matsuno, T., 1966: Quasi-geostrophic motions in the equatorial area. J. Meteor. Soc. Japan, 44, 25-43, https://doi.org/10.2151/jmsj1965.44.1_25. 
Patel, A. C., 2001: Modulation of African lightning and rainfall by the global five day wave. M.S. thesis, Dept. of Mechanical Engineering, Massachusetts Institute of Technology, 176 pp., https://hdl.handle .net/1721.1/16766.

Rossby, C.-G., and Coauthors, 1939: Relation between variations in the intensity of the zonal circulation of the atmosphere and the displacements of the semipermanent centers of action. J. Mar. Res., 2, 38-55, https://doi.org/10.1357/002224039806649023.

Rüfenacht, R., K. Hocke, and N. Kämpfer, 2016: First continuous ground-based observations of long period oscillations in the vertically resolved wind field of the stratosphere and mesosphere. Atmos. Chem. Phys., 16, 4915-4925, https://doi.org/10.5194 /acp-16-4915-2016.

Salby, M. L., 1984: Survey of planetary-scale traveling waves: Theory and observations. Rev. Geophys. Space Phys., 22, 209-236, https://doi.org/10.1029 /RG022i002p00209.

Sassi, F., R. R. Garcia, and K. W. Hoppel, 2012: Largescale Rossby normal modes during some recent Northern Hemisphere winters. J. Atmos. Sci., 69, 820-839, https://doi.org/10.1175/JAS-D-11-0103.1.

Swarztrauber, P. N., and A. Kasahara, 1985: The vector harmonic analysis of Laplace's tidal equations. SIAM J. Sci. Stat. Comput., 6, 464-491, https://doi .org/10.1137/0906033.

Van Loon, H., R. L. Jenne, and K. Labitzke, 1973: Zonal harmonic standing waves. J. Geophys. Res., 78, 44634471, https://doi.org/10.1029/JC078i021p04463.

Wallace, J. M., 1971: Spectral studies of tropospheric wave disturbances in the tropical western Pacific. Rev. Geophys., 9, 557-612, https://doi.org/10.1029 /RG009i003p00557.

— , and V. E. Kousky, 1968: Observational evidence of Kelvin waves in the tropical stratosphere. J. Atmos.
Sci., 25, 900-907, https://doi.org/10.1175/1520-0469 (1968)025<0900:OEOKWI>2.0.CO;2.

_ , and C.-P. Chang, 1969: Spectrum analyses of large-scale wave disturbances in the tropical lower troposphere. J. Atmos. Sci., 26, 1010-1025, https:// doi.org/10.1175/1520-0469(1969)026<1010:SAOLS $\mathrm{W}>2.0 . \mathrm{CO} ; 2$.

Yanai, M., and T. Maruyama, 1966: Stratospheric wave disturbances propagating over the equatorial $\mathrm{Pa}$ cific. J. Meteor. Soc. Japan, 44, 291-294, https://doi .org/10.2151/jmsj1965.44.5_291.

$\_, \ldots$, T. Nitta, and Y. Hayashi, 1968: Power spectra of large-scale disturbances over the tropical Pacific. J. Meteor. Soc. Japan, 46, 308-323, https://doi .org/10.2151/jmsj1965.46.4_308.

Žagar, N., A. Kasahara, K. Terasaki, J. Tribbia, and H. Tanaka, 2015: Normal-mode function representation of global 3-D data sets: Open access software for the atmospheric research community. Geosci. Model Dev., 8, 1169-1195, https://doi.org/10.5194 /gmd-8-1169-2015.

— , J. Boyd, A. Kasahara, J. Tribbia, E. Källén, H. Tanaka, and J.-I. Yano, 2016: Normal modes of atmospheric variability in observations, numerical weather prediction, and climate models. Bull. Amer. Meteor. Soc., 97, ES125-ES128, https://doi .org/10.1175/BAMS-D-15-00325.1.

Zipser, E. J., 1969: The role of organized unsaturated convective downdrafts in the structure and rapid decay of an equatorial disturbance. J. Appl. Meteor., 8, 799-814, https://doi.org/10.1175/1520 -0450(1969)008<0799:TROOUC>2.0.CO;2.

_ 1970: The Line Islands Experiment, its place in tropical meteorology and the rise of the fourth school of thought. Bull. Amer. Meteor. Soc., 51, 1136-1146, https://doi.org/10.1175/1520-0477-51.12.1136. 


\section{AMS BOOKS RESEARCH APPLICATIONS HISTORY}

The Thinking Person's Guide to Climate Change ROBERT HENSON

This fully updated and expanded revision of The Rough Guide to Climate Change combines years of data with recent research. It is the most comprehensive overview of climate science, acknowledging controversies but standing strong in its stance that the climate is changing-and something needs to be done.

(c) 2014, PAPERBACK, 520 PAGES,

ISBN: 978-1-935704-73-7

LIST \$30 MEMBER \$20
CLIMATE

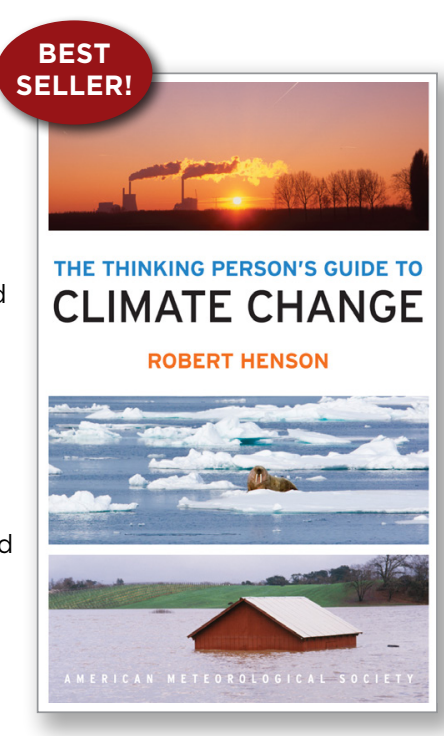

\section{Climate Conundrums:} What the Climate Debate Reveals about Us

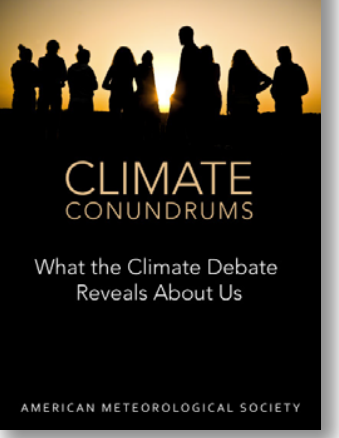

WILLIAM B. GAIL

This is a journey through how we think, individually and collectively, about humanity's relationship with nature, and more. Can we make nature better? Could science and religion reconcile? Gail's insights on such issues help us better understand who we are and find a way forward.

(c) 2014, PAPERBACK, 240 PAGES, ISBN: 978-1-935704-74-4 LIST \$30 MEMBER \$20

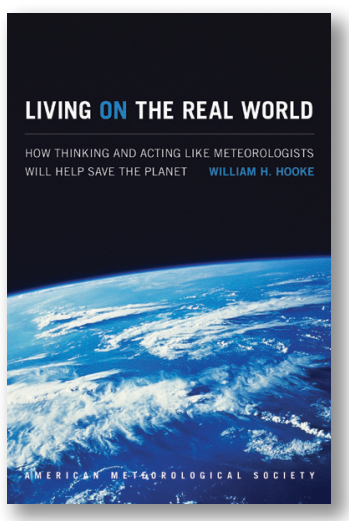

\section{Living on the}

\section{Real World:}

How Thinking and Acting Like Meteorologists

Will Help Save the Planet WILLIAM H. HOOKE

Meteorologists focus on small bits of information while using frequent collaboration to make decisions. With climate change a reality, William $\mathrm{H}$. Hooke suggests we look to the way meteorologists operate as a model for how we can solve the 21st century's most urgent environmental problems.

(c) 2014, PAPERBACK, 272 PAGES, ISBN 978-1-935704-56-0 LIST \$30 MEMBER \$22

\section{Synoptic-Dynamic Meteorology Lab Manual:}

Visual Exercises to Complement Midlatitude Synoptic Meteorology

\section{GARY LACKMANN, BRIAN E. MAPES, AND KEVIN R. TYLE}

These labs link theoretical concepts with groundbreaking visualization to elucidate concepts taught in the award-winning companion textbook by Gary Lackmann, Midlatitude Synoptic Meteorology.

(c) 2017, PAPERBACK, 126 PAGES, ISBN 978-1-878220-26-4 LIST \$80 MEMBER \$60 STUDENT \$50

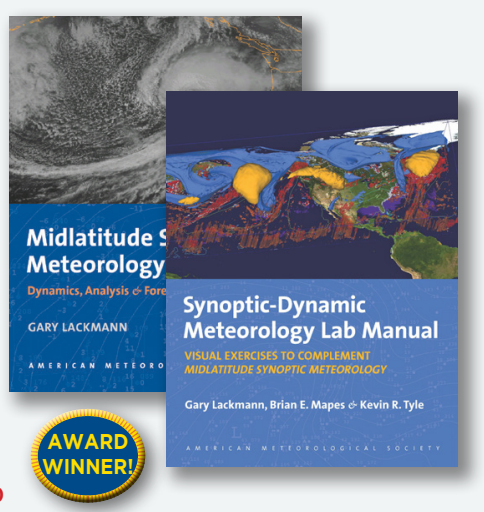

\section{GUIDES}

\section{An Observer's Guide to Clouds}

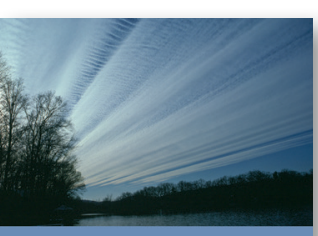

AN OBSERVER'S GUIDE CLOUDS AND WEATHER A NORTHEASTERN PRIMER ON PREDICTION TOEY GARISON, PAUL KNIGH, ANO GELLA WYCKOFF

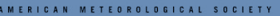
and Weather:

A Northeastern Primer on Prediction

TOBY CARLSON, PAUL KNIGHT, AND CELIA WYCKOFF

With help from Penn State experts, start at the beginning and go deep. This primer, intended for both serious enthusiasts and new meteorology students, will leave you with both refined observation skills and an understanding of the complex science behind the weather: the ingredients for making reliable predictions of your own. It connects fundamental meteorological concepts with the processes that shape

weather patterns, and will make an expert of any dedicated reader.

(c) 2014, PAPERBACK, 210 PAGES,

ISBN: 978-1-935704-58-4 LIST \$30 MEMBER \$20

\section{Eloquent Science:}

A Practical Guide to Becoming a Better Writer, Speaker, and Atmospheric Scientist DAVID M. SCHULTZ

The ultimate communications manual for undergraduate and graduate students as well as researchers in the atmospheric sciences and their intersecting disciplines.

(c) 2009, PAPERBACK, 440 PAGES, ISBN 978-1-878220-91-2

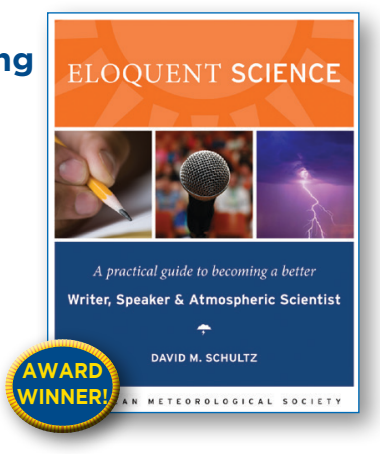

LIST \$45 MEMBER \$30 


\section{SHIPPING + DISCOUNTS AT BOOKSTORE.AMETSOC.ORG}

NEW

Verner Suomi: The Life and Work of the Founder of Satellite Meteorology

JOHN M. LEWIS WITH JEAN M. PHILLIPS, W. PAUL MENZEL, THOMAS H. VONDER HAAR, HANS MOOSMÜLLER, FREDERICK B. HOUSE, AND MATTHEW G. FEARON

Born in a Minnesotan mining town, Suomi would spend his best years next door in Wisconsin, but not before seeing the whole world-from space, that is. This is the story of the scientist, inventor, and teacher who founded satellite meteorology, written by members of the communities that grew up around his groundbreaking work.

LIST \$3O MEMBER \$20

(c) 2016, PAPERBACK, 240 PAGES, ISBN: 978-1-944970-22-2

\section{Weather in the Courtroom: Memoirs from a Career iForensic Meteorology}
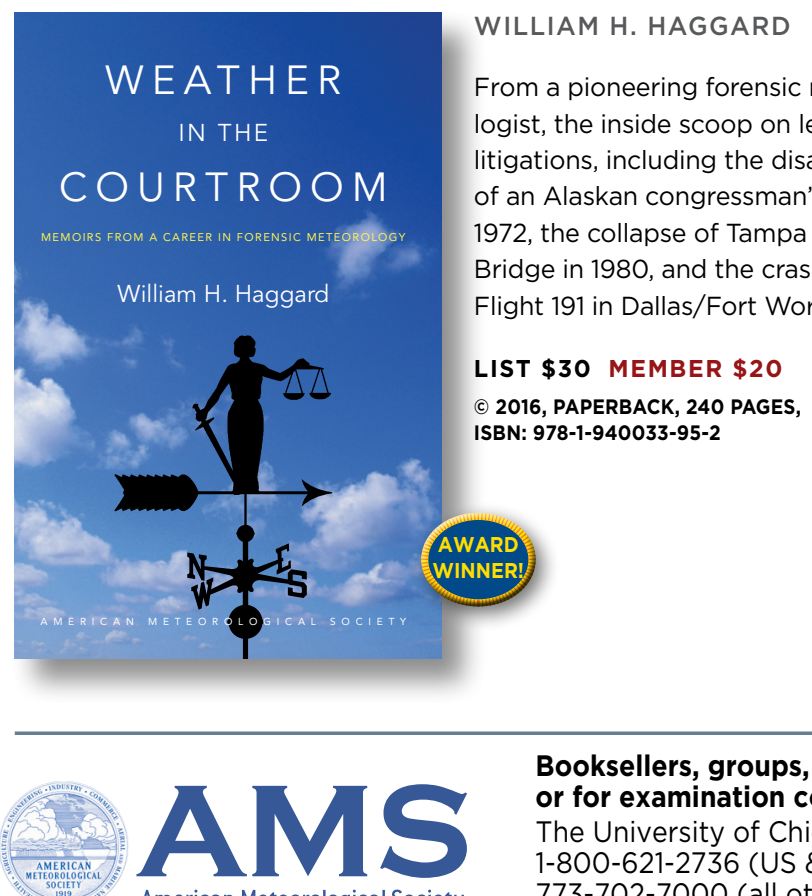

American Meteorological Society

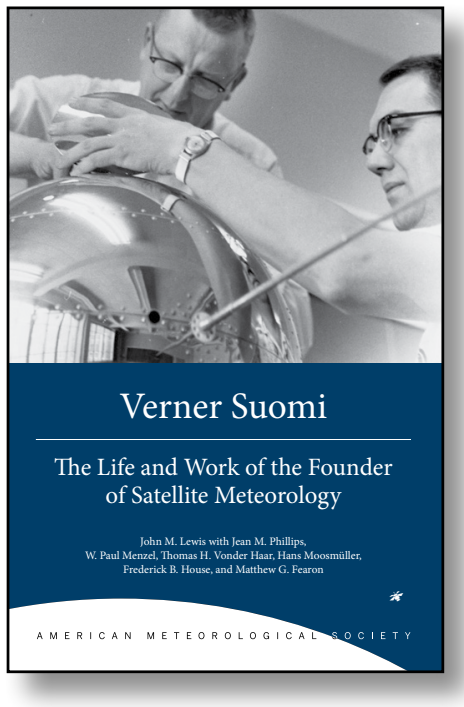

HISTORY

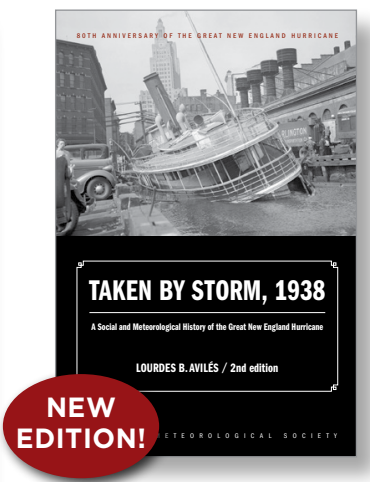

Taken by Storm, 1938:

A Social and Meteorological History of the Great New England Hurricane, 2nd Ed. LOURDES B. AVILÉS

The science behind 80TH
ANNIVERSARY OF STORM the 1938 Hurricane, which hit New England unannounced, is presented here for the first time along with new data that

sheds light on the motivations of the Weather Bureau forecasters. This compelling history successfully weaves science, historical accounts, and social analyses to create a comprehensive picture of the most powerful and devastating hurricane to hit New England to date.

(c) 2018, PAPERBACK, 288 PAGES, ISBN: 978-1-944970-24-6 LIST \$30 MEMBER \$20

\section{A Scientific Peak:}

How Boulder Became a World Center for Space and Atmospheric Science

JOSEPH P. BASSI

How did big science come to Boulder, Colorado? Joe Bassi introduces us to the characters, including Harvard sun-Earth researcher Walter Orr Roberts, and the unexpected brew of politics, passion, and sheer luck that during the Cold War era transformed this "Scientific Siberia" to home of NCAR and NOAA

(c) 2015, PAPERBACK, 264 PAGES, ISBN: 978-1-935704-85-0 LIST PRICE: $\$ 35.00$ MEMBER PRICE: $\$ 25.00$

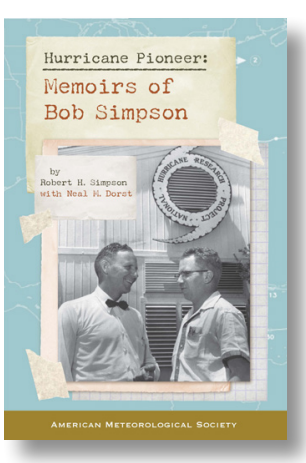
Hurricane Pioneer: Memoirs of Bob Simpson ROBERT H. SIMPSON AND NEAL DORST

In 1951, Bob Simpson rode a plane into a hurricane-just one of the many pioneering exploits you'll find in these memoirs. Bob and his wife Joanne are meteorological icons: Bob was the first director of the National Hurricane Research Project and a director of the National Hurricane Center. He helped to create the Saffir-Simpson Hurricane Scale; the public knows well his Categories 1-5. Proceeds from this book help support the AMS's K. Vic Ooyama Scholarship Fund.

(c) 2015, PAPERBACK, 156 PAGES

ISBN: 978-1-935704-75-1 LIST \$25 MEMBER \$2O 
